\title{
Association between dietary vitamin D intake and serum lipid profiles in Asian and Caucasian UK women: preliminary results from the Vitamin D, Food Intake, Nutrition and Exposure to Sunlight in Southern England (D-FINES) Study
}

\author{
Susan Lanham-New ${ }^{1}$, Puikwan Lee ${ }^{1}$, Max Wong ${ }^{1}$, Carol Sui ${ }^{1}$, Sue Starkey ${ }^{1}$, David Lovell ${ }^{1}$, \\ Jacqueline Berry ${ }^{2}$ and Bruce Griffin ${ }^{1}$ \\ ${ }^{1}$ University of Surrey, Guildford, UK and ${ }^{2}$ University of Manchester, Manchester, UK
}

Vitamin D is the generic term for two molecules, ergocalciferol (vitamin $\mathrm{D}_{2}$ ) and cholecalciferol (vitamin $\mathrm{D}_{3}$ ). The former is derived by UV irradiation of the ergosterol, which is widely distributed in plants and fungi, whereas the latter is formed from the action of UV irradiation on the skin ${ }^{(1)}$. There are few dietary sources of vitamin D. Vitamin D deficiency has been associated with insulin resistance, $\beta$-cell dysfunction and reduced insulin secretion. It has also been implicated as a risk factor for metabolic syndrome, hypertension and types 1 and 2 diabetes, all of which may explain its links with increased CVD ${ }^{(2)}$. These findings are particularly apparent in Asian groups and may underlie the considerable predisposition to CVD in this group ${ }^{(3)}$. There is evidence to suggest that vitamin D deficiency is associated with raised serum total cholesterol and LDL-cholesterol and inversely related to the serum concentration of cardioprotective $\mathrm{HDL}^{(4)}$, although this relationship needs to be more widely confirmed in well-controlled cohort and intervention studies.

The D-FINES Study is currently investigating the effect of diet and sunlight exposure on vitamin D status in women aged 19-70 years. Fasted blood samples were collected every 3 months from summer 2006 to spring 2007 for a total of 227 Caucasian and seventy-two Asian women and dietary intake assessed using $4 \mathrm{~d}$ estimated food records. The aim of the present subsidiary study was to determine the association between dietary intake of vitamin D and serum lipid profiles, including TAG, LDL- and HDL-cholesterol and LDL:HDL.

\begin{tabular}{|c|c|c|c|c|c|c|c|c|c|}
\hline \multirow[b]{2}{*}{ Variable } & \multicolumn{2}{|c|}{ Caucasian women } & \multicolumn{2}{|c|}{ Asian women } & \multirow[b]{2}{*}{ Variable } & \multicolumn{2}{|c|}{ Caucasian women } & \multicolumn{2}{|c|}{ Asian women } \\
\hline & Mean & SD & Mean & $\mathrm{SD}$ & & Mean & SD & Mean & SD \\
\hline Age (years) & 50.4 & 14.3 & 49.7 & 11.6 & Cholesterol $(\mathrm{mmol} / \mathrm{l})$ & 5.13 & 1.24 & 4.68 & 0.86 \\
\hline BMI $\left(\mathrm{kg} / \mathrm{m}^{2}\right)$ & $26.2^{\mathrm{a}}$ & 5.2 & $28.6^{\mathrm{b}}$ & 6.1 & $\operatorname{HDL}-\mathrm{C}(\mathrm{mmol} / \mathrm{l})$ & 1.67 & 0.47 & 1.48 & 0.36 \\
\hline Vitamin D intake $(\mu \mathrm{g} / \mathrm{d})$ & 2.82 & 2.43 & 2.77 & 1.79 & LDL-C (mmol/l) & 2.87 & 0.93 & 2.58 & 0.71 \\
\hline TAG $(\mathrm{mmol} / \mathrm{l})$ & $1.12^{\mathrm{a}}$ & 0.65 & $1.35^{\mathrm{b}}$ & 0.58 & LDL:HDL & 1.86 & 0.69 & 1.83 & 0.60 \\
\hline
\end{tabular}

Means with unlike superscript letters were significantly different (Mann Whitney $\mathrm{U}$ test; $P<0.05$ ).

The concentration of serum lipids and lipoproteins were all well within clinical action limits. BMI and TAG were significantly higher in the Asian women compared with the Caucasian subjects, but no differences were found for LDL:HDL. Dietary intake of vitamin D was similar between the two groups but was significantly associated with both serum TAG $(P<0.001)$ and total cholesterol $(P<0.05)$ for the Caucasian women, but not for the Asian women. When vitamin D intake was stratified into quartiles (Q; 1-4), higher intakes were associated with lower serum TAG in the Caucasian group (lowest vitamin D Q1, TAG 1.32 mmol/l to highest Q4, TAG 0.977 mmol/l; F test for linearity, $P=0.037$ ). There was no evidence of any associations in the Asian population.

Measurement of 25-hydroxyvitamin D status is currently underway. These data in turn will enable the establishment of the importance of ethnicity on the relationship between vitamin D status and these lipid markers of cardiovascular risk in both Asian and Caucasian women.

This work was funded by the Food Standard Agency (N05064). The views expressed are the authors' own. The authors are indebted to the following individuals for their help with subject recruitment: Mrs R Hanjra and Mrs R Killedar, Islamic Resource Centre, Kingston; Mrs S Bano, Woking Khidmat Group; Mrs R Mahoon, Woking Asian Women's Association; Mrs R Mahendran, Thornton Health Asian Association; Mrs F Smithers, College Road Surgery, Woking; the late Mr John Pheasant, Thornton Health Medical Centre.

1. Holick MF (2002) Curr Opin Endocrinol Diabetes Obes 9, 87-98.

2. Chiu KC, Chu A, Go VLW \& Saad MF (2004) Am J Clin Nutr 79, 820-825.

3. Boucher B (2006) Diabet Med 23, 335-336.

4. Chiu KC et al (2004) Am J Clin Nutr 79, 820-825. 